\title{
ESTIMATIVAS DE BIOMASSA E CARBONO EM ÁREA DE MATA ATLÂNTICA, IMPLANTADA POR MEIO DE REFLORESTAMENTO MISTO
}

\author{
ESTIMATES OF BIOMASS AND CARBON IN AN ATLANTIC FOREST AREA, IMPLEMENTED \\ BY MIXED REFORESTATION
}

\author{
Anne Caroline Silva Meira ${ }^{1}$, Anabel Aparecida de Mello ${ }^{2}$, Carlos Roberto Sanquetta ${ }^{3}$ Robério \\ Anastácio Ferreira ${ }^{4}$ \\ 1, 2,4 Universidade Federal de Sergipe, São Cristóvão, Sergipe, Brasil - anneflorestal@gmail.com, \\ anabel_mello@yahoo.com.br\& roberioraf@yahoo.com.br \\ ${ }_{3}^{3}$ Universidade Federal do Paraná, Curitiba, Paraná, Brasil - carlossanquetta@gmail.com
}

RESUMO

\begin{abstract}
Ecossistemas florestais são muito importantes no processo de estocagem do carbono presente na atmosfera, e as áreas de reflorestamentos mistos podem contribuir substancialmente nesse processo. Em virtude disso, o conhecimento sobre o papel das florestas na manutenção da integridade dos ecossistemas e na mitigação dos efeitos antrópicos sobre estes, contribui efetivamente para a criação de ações e políticas de conservação e restauração florestal. Neste sentido, este trabalho foi realizado com o objetivo de avaliar uma área de reflorestamento misto com 11 anos de idade, sob domínio do Bioma Mata Atlântica no município de Laranjeiras, Sergipe, através da estimativa de biomassa e carbono. O levantamento de dados foi realizado por meio de três inventários florestais consecutivos numa área de $48 \mathrm{~h}$. Foram instaladas 30 parcelas de $600 \mathrm{~m}^{2}$ totalizando $1,8 \mathrm{ha}$ de área amostrada, onde foram mensuradas a circunferência à altura do peito (CAP) e altura total e identificados todos os indivíduos com CAP $\geq 15 \mathrm{~cm}$. A quantificação da biomassa e do teor de carbono foi estimada pelo método indireto. Os estoques totais de biomassa e carbono acima do solo foram de 15,64 t.ha-1 e 6,44 t.ha-1, respectivamente para o ano de 2014, aumentando em 2015 para 18,44 t.ha-1 e 7,59 t.ha-1 e em 2016 para 21,13 t.ha-1 e 8,70 t.ha ${ }^{-1}$. O incremento periódico anual (IPA) obtido foi de 2,7 t.ha $a^{-1}$.ano $o^{-1}$ para a biomassa e 1,1 t.ha $^{-1}$.ano-1 para o carbono. A área em processo de restauração está contribuindo de forma significativa para a conservação da biodiversidade e para o fornecimento de serviços ambientais, como o sequestro de carbono.
\end{abstract}

PALAVRAS-CHAVE: Estoque de carbono, Mata Atlântica, Restauração florestal.

\section{ABSTRACT}

Forest Ecosystems are extremely important for carbon stock process found out in the atmosphere and mixed reforestation areas can help in this process. In this way, the knowledge about the forest role on the ecosystem integrity maintenance and mitigation on anthropic effects, contributes effectively to create actions for conservation and forest reforestation politics. The present study was carried out to evaluate a mixed reforestation area with 11 years old, Atlantic Forest Biome in Laranjeiras, Sergipe, through biomass and carbon estimation. Data collection was carried out through three consecutive forest inventories in an area of 48ha, where circumference at breast high (CBH) and total height were measured, for all the trees with $\mathrm{CBH} \geq 15 \mathrm{~cm}$. The biomass quantification and the carbon content was estimated using the direct method. Total biomass and carbon stocks above the ground were 15,64 t.ha ${ }^{-1}$ and 6,44 t.ha ${ }^{-1}$, respectively for the 2014 year, getting higher in 2015 to 18,44 t.ha ${ }^{-1}$ and 7,59 t.ha-1 and in 2016 to 21,13 t.ha ${ }^{-1}$ and 8,70 t.ha ${ }^{-1}$. The annual periodic increment (IPA) obtained was 2,7 t.ha ${ }^{-1} \cdot \mathrm{year}^{-1}$ to biomass and 1,1 t.ha ${ }^{-1}$.year ${ }^{-1}$ to carbon. The area in restation process is contributing in a significate way for the provision of environmental services, such as carbon sequestration.

KEYWORDS: Atlantic Forest, Carbon stock, Forest restoration. 


\section{INTRODUÇÃO}

A ação antrópica e a exploração descontrolada dos recursos naturais estão entre as principais causas da degradação e fragmentação dos ecossistemas naturais (NOSSACK et al., 2011). Dentre os efeitos negativos gerados, está o aumento da concentração de gases do efeito estufa (GEE) na atmosfera, principalmente do $\mathrm{CO}_{2}$, promovendo mudanças significativas nos padrões climáticos globais (RIBEIRO et al., 2010; ZIEMMER et al., 2016).

Atualmente, é reconhecido que as florestas exercem um papel fundamental na ciclagem do $\mathrm{CO}_{2}$ presente na atmosfera (BRITEZ et al., 2006). As florestas atuam como fonte de liberação do $\mathrm{CO}_{2}$ em decorrência da queima e do desmatamento da cobertura florestal, porém, ao mesmo também desempenham a função de sumidouros desse elemento, uma vez que as árvores armazenam carbono por meio da fotossíntese (MIRANDA, 2008; PEREIRA, 2013). Além de outros fatores o estoque e o sequestro do carbono estão relacionados com as espécies, manejo dos plantios e a sucessão ecológica em florestas nativas (SOUZA et al., 2012).

A preservação do estoque de carbono existente nas florestas, através da proteção dos remanescentes naturais; o aumento do estoque de carbono florestal por meio de práticas de manejo sustentável, regeneração florestal, florestamento e reflorestamento em áreas degradadas; e a substituição de combustíveis fósseis por produtos de biomassa de origem vegetal, de forma sustentável, são formas válidas e legítimas de mitigar a emissão de carbono através das florestas (CHANG, 2002; BRITEZ et al., 2006). Com isso, o cultivo de florestas é uma alternativa para diminuir os efeitos das mudanças do clima e da degradação do ambiente em geral (SANQUETTA et al., 2011).

Dessa forma, o conhecimento sobre o potencial de fixação e estoque de carbono por espécies florestais, contribui efetivamente na elaboração e avaliação de estratégias de conservação, como também para a restauração dos recursos naturais em longo prazo (SILVA NETO, 2011; WATZLAWICK et al., 2011).

A mensuração da biomassa pode ser efetuada utilizando-se métodos diretos ou indiretos, sendo que o método direto consiste em cortar, separar e pesar seus elementos (WATZLAWICK, 2003). Já através do método indireto, onde são feitas estimativas, podem ser utilizadas imagens de satélite ou funções alométricas (SANQUETTA et al., 2014).

Dentre eles, a avaliação do estoque de biomassa através de variáveis dendrométricas de fácil mensuração, como o diâmetro à altura do peito (DAP) e altura total, é fundamental para entender o comportamento do estoque do carbono com o crescimento dos indivíduos, não necessitando também recorrer a métodos diretos, como o corte e pesagem total das árvores (SANQUETTA et al., 2003; MOGNON et al., 2011).

A Mata Atlântica foi um dos biomas brasileiros que mais sofreu com a intervenção humana, principalmente em se tratando de desmatamentos, o que contribui diretamente para que o carbono que estava estocado na biomassa florestal fosse emitido para atmosfera (RIBEIRO, 2007). Segundo o Serviço Florestal Brasileiro (2017), no estado de Sergipe restam apenas $13 \%$ de Mata Atlântica. Dessa forma, o referido bioma apresenta um grande potencial para o estabelecimento de projetos que visem recompor suas áreas degradadas e assim, aumentar o estoque de carbono em seus ecossistemas.

Apesar do crescente interesse em se conhecer os estoques de carbono existentes em diferentes ecossistemas, há muito em que se avançar acerca das estimativas confiáveis sobre a dinâmica das florestas nativas, principalmente pela escassez de informações sobre essa dinâmica em longos ciclos (CORTE et al., 2012).

Considerando-se a carência de estudos sobre a fixação de carbono em florestas em processo de restauração pertencentes ao Bioma Mata Atlântica, este trabalho foi realizado com o objetivo de quantificar a biomassa aérea e o estoque de carbono em árvores, em uma área em processo de restauração florestal destinada a compor a reserva legal da empresa Votorantim Cimentos S.A., no Município de Laranjeiras, Sergipe.

\section{MATERIAL E MÉTODOS}

\section{Descrição da área de estudo}

A área de estudo está localizada a leste do território sergipano, no município de Laranjeiras, à aproximadamente 25 quilômetros da capital Aracaju entre as coordenadas $10^{\circ} 48^{\prime} 22^{\prime \prime}$ de latitude Sul e $37^{\circ} 10^{\prime} 18^{\prime \prime}$ de longitude Oeste, na microrregião do baixo Cotinguiba (SERGIPE, 1976) (Figura 1).

A vegetação natural da área corresponde ao bioma Mata Atlântica e o clima predominante é o megatérmico seco e sub-úmido, com uma precipitação média anual de $1.279 \mathrm{~mm}$ e uma temperatura média anual de $25,2^{\circ} \mathrm{C}$ (BARRETO e ALMEIDA, 2007).

A área total que abrange 46 ha, pertence à empresa Votorantim Cimentos (S.A.) e foi implantada nos anos de 2004 e 2005, como medida compensatória aos impactos 
causados ao meio ambiente por suas atividades empreendedoras e com o objetivo de compor a reserva legal da empresa.

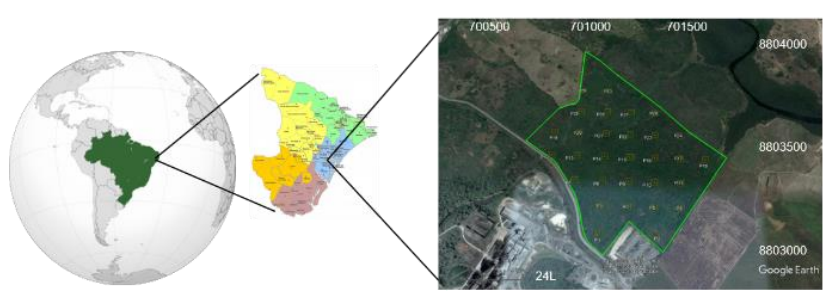

Figura 1. Localização da área de reflorestamento misto, no município de Laranjeiras, Sergipe. (Mapa da área elaborado por João Luis de Mello, 2019).

\section{Coleta e análise de dados}

A coleta dos dados foi iniciada no ano de 2014, com a instalação de 30 parcelas permanentes distribuídas sistematicamente na área de estudo. As parcelas instaladas possuem área de $600 \mathrm{~m}^{2}(30 \mathrm{~m} \times 20 \mathrm{~m})$ e estão equidistantes entre si a $127 \mathrm{~m}$, perfazendo uma área amostrada de 1,8 ha.

Os indivíduos arbóreos tiveram suas CAPs (circunferência à 1,30 m) e alturas totais medidas com o auxílio de fita métrica e vara telescópica, respectivamente, em três inventários florestais consecutivos, sendo o critério mínimo de inclusão a CAP $\geq 15 \mathrm{~cm}$, medida a 1,30 $\mathrm{m}$ acima do solo. Além das variáveis mensuradas, foram coletados materiais botânicos para identificação das espécies existentes na área. O sistema de classificação adotado foi Angiosperm Phylogeny Group III (APG III, 2009).

Tendo em vista o estudo ter sido realizando em uma área de compensação ambiental, onde não seria possível o abate dos indivíduos para a determinação da biomassa (método direto), foi utilizada a equação alométrica desenvolvida por SANQUETTA et al. (2018) em povoamentos jovens de restauração florestal, em Rondônia.

$\log ($ biomassa total seca $)=-0,717903255+$ $0,940214879 \cdot \log ($ dap $)+1,345432588 \cdot \log (h t) \cdot 1,109844005$

Em que: $d a p=$ diâmetro à 1,30 m; e $h t=$ altura total.

A partir dessa equação foi possível obter a estimativa de biomassa em kg. Para a conversão da biomassa (t) em carbono ( $t$ ) utilizou-se o fator $41,2 \%$, encontrado por VIEIRA et al. (2009), através de determinação direta pelo método de combustão a seco.

\section{RESULTADOS E DISCUSSÃO}

$\mathrm{Na}$ realização do inventário florestal, foram mensurados no ano de 2014, 788 indivíduos, aumentando em 2015 para 819 e em 2016 para 833, contabilizando 22 espécies e 8 famílias botânicas.

Por se tratar de uma área de formação florestal heterogênea, com diferentes estágios sucessionais, a estimativa da biomassa nas 30 unidades amostrais instaladas apresentou valores variando entre 0,20 t.ha- ${ }^{-1} \mathrm{e}$ 1,64 t.ha ${ }^{-1}$.

Verificou-se o aumento gradual da biomassa aérea total com o avanço da idade do reflorestamento. A biomassa total arbórea acima do solo estimada no primeiro ano de medição (2014) foi de 15,64 t.ha ${ }^{-1}$, aumentando em 2016 para 21,13 t.ha ${ }^{-1}$, como pode ser observado na Figura 2. O IPA de biomassa total arbórea foi de 2,74 t.ha $^{-1}$.ano-1, enquanto que o IPA para o carbono foi de 1,15 t.ha ${ }^{-1}$.ano ${ }^{-1}$.

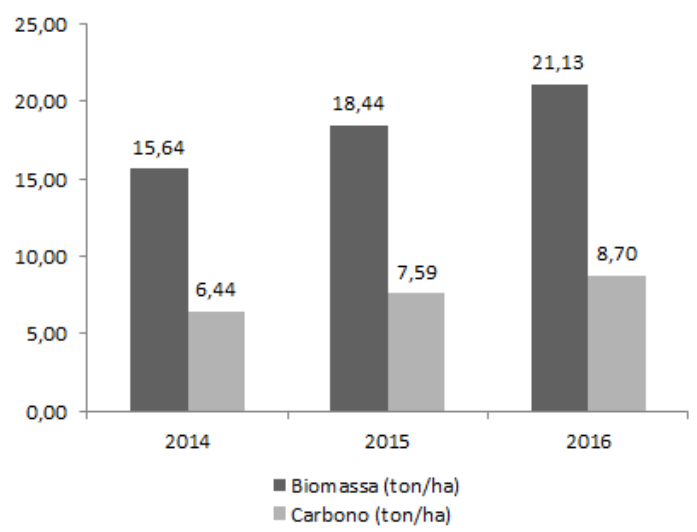

Figura 2. Dinâmica do estoque de biomassa da área de reflorestamento misto, pertencente a Empresa Votorantim Cimentos S.A., localizada no município de Laranjeiras, Sergipe.

Barreto et al. (2014), analisando o estoque de biomassa de fragmento urbano de Floresta Ombrófila Mista, durante um período de 5 anos, em Curitiba, encontraram os valores de 236,6 t.ha-1 para o ano de 2009 e 257,2 t.ha-1 em 2013, sendo o IPA de 5,16 t.ha ${ }^{-1}$.ano ${ }^{-1}$. Os valores observados pelos referidos autores são maiores em relação aos encontrados neste trabalho. $\mathrm{O}$ fator mais importante para esse resultado é a idade deste plantio, de apenas 11 anos, caracterizando uma área jovem em processo de restauração.

Além disso, neste estudo foram considerados apenas os indivíduos com CAP $\geq 15 \mathrm{~cm}$ (Circunferência à 1,30 m), logo uma parcela da biomassa e do carbono na forma de regeneração natural deixou de ser contabilizada. Em contrapartida, apesar do baixo valor da estimativa da 
biomassa, a área de restauração em estudo apresentou expressivo incremento $\left(2,73 \mathrm{t}^{\mathrm{h}} \mathrm{ha}^{-1} \cdot \mathrm{ano}^{-1}\right)$ para o período de 2 anos.

Em área de restauração em Floresta Semidecidual, no município de Itutinga, MG, Silva (2014) encontrou valores de incremento periódico anual do estoque de carbono variando entre 0,22 t.ha ${ }^{-1}$. ano ${ }^{-1}$ e 1,11 t.ha ${ }^{-1}$. ano ${ }^{-1}$ entre as unidades amostrais, com um valor médio de 0,61 t.ha ${ }^{-1}$.ano ${ }^{-1}$. As diferenças verificadas no potencial de fixação de carbono, entre as diferentes áreas florestais, refletem a variação de inúmeros fatores, incluindo a composição da comunidade arbórea, o histórico de perturbação, o estágio sucessional, além de condições climáticas e edáficas.

Segundo o Serviço Florestal Brasileiro, o estoque de biomassa aérea no Bioma Mata Atlântica é em média 66 t.ha ${ }^{-1}$ (SFB, 2010). O valor médio encontrado nas avalições realizada neste estudo foi de 18,40 t.ha-1. Sendo assim portanto considerada uma área em estágio inicial de sucessão, apresentando baixa taxa de biomassa e carbono fixado, mas com boa taxa de incremento.

Ao longo da sucessão ecológica, ocorre o incremento de biomassa em florestas tropicais em função do aumento na diversidade de espécies de estágios sucessionais mais avançados, que apresenta maior volume e longo ciclo de vida, consequentemente abriga um maior estoque de biomassa e carbono (CHAZDON, 2012). Além disso, tendo em vista que a biomassa está relacionada com a idade da floresta e o grupo ecológico das espécies, o seu acúmulo em projetos de restauração pode variar bastante (BORGES et al., 2017).

Analisando-se o estoque de biomassa por grupo de espécies, observou-se que Schinus terebinthifolia Raddi, do grupo das pioneiras, apresentou os maiores valores de biomassa durante as três avaliações realizadas, 6,78 t.ha ${ }^{-1}$ em 2014, 7,61 t.ha-1 em 2015 e 8,90 t.ha-1 em 2016, sendo a média 7,76 t.ha $^{-1}$ (Tabela 1). Esse resultado pode estar relacionado à abundância de espécies pioneiras empregadas no plantio, que corresponderam a cerca de $53,3 \%$ da biomassa total. Além de contribuir com o estoque total de biomassa, esse grupo sucessional também contribuiu efetivamente para o IPA da área, devido ao crescimento acelerado das espécies que o compõem.

A estimativa da biomassa encontrada na área de estudo foi considerada baixa quando comparado aos resultados obtidos em trabalhos de mesmo cunho, contudo, como a área encontra-se em processo de desenvolvimento sucessional, espera-se que o estoque de biomassa e carbono aumente nos próximos anos, em consequência do crescimento da floresta.
Tabela 1. Estimativa média da biomassa para os três anos de avaliação, das espécies de maior contribuição com a biomassa total, em área de reflorestamento misto, pertencente a Empresa Votorantim Cimentos S.A., localizada no município de Laranjeiras, Sergipe.

\begin{tabular}{ccccc}
\hline Espécie & Nome Popular & \multicolumn{3}{c}{ Biomassa (t.ha $^{-1}$ ) } \\
\hline & & $\mathbf{2 0 1 4}$ & $\mathbf{2 0 1 5}$ & $\mathbf{2 0 1 6}$ \\
\hline Schinus terebinthifolia Raddi & Aroeira & 6,78 & 7,61 & 8,90 \\
Cassia grandis L.f. & Canafístula & 3,19 & 3,62 & 4,02 \\
Enterolobium contortisiliquum (Vell.) Morong & Tamboril & 1,03 & 1,25 & 1,41 \\
Lonchocarpus sericeus (Poir.) Kunth ex DC. & Falso-Ingá & 0,96 & 1,17 & 1,44 \\
Genipa americana L. & Jenipapo & 0,69 & 0,84 & 0,97 \\
Inga vera Willd. & Ingá & 0,69 & 1,02 & 1,08 \\
Syzygium jambolanum (Lam.) DC. & Jamelão & 0,64 & 0,88 & 1,08 \\
Erythrina velutina Willd. & Mulungu & 0,54 & 0,65 & 0,72 \\
Guazuma ulmifolia Lam. & Mutamba & 0,31 & 0,32 & 0,35 \\
Anadenanthera macrocarpa (Benth.) Brenan & Angico & 0,27 & 0,41 & 0,40 \\
\hline
\end{tabular}

As informações geradas por esse estudo podem fornecer suporte para programas de conservação de florestas naturais e de restauração de áreas degradadas visando promover a manutenção da biodiversidade local e, consequentemente, o aumento do estoque de carbono no local. E ainda, é possível buscar-se formas de comercialização de créditos de carbono florestal pela redução de emissões por desmatamento e degradação das florestas naturais. Dessa forma há uma necessidade de realização de mais estudos de quantificação de carbono em outras áreas de domínio do bioma Mata Atlântica no estado de Sergipe, para geração de informações que possam compor um banco de dados.

\section{CONCLUSÕES}

Os resultados obtidos neste estudo, quando comparados com outros trabalhos publicados, mostram que o total de carbono acumulado na biomassa aérea é considerado baixo, podendo estar relacionado ao processo de restauração, e a área encontrar-se em estágio de sucessão inicial.

Dentre as espécies identificadas, Schinus terebinthifolia Raddi teve a maior contribuição no acúmulo de carbono na área.

A biomassa e o estoque de carbono aumentaram conforme o incremento em idade. Portanto, esses valores tendem a aumentar de acordo com o desenvolvimento do reflorestamento, mostrando assim a importância dessas formações florestais no sequestro de carbono atmosférico.

Sugere-se, em estudos futuros, que se avalie também a biomassa da regeneração natural e outros reservatórios, além de fornecer estimativas mais precisas do estoque de 
carbono pelas florestas, permite conhecer melhor a dinâmica do ciclo do carbono.

\section{REFERÊNCIAS}

BARRETO, E.A.S.; ALMEIDA, E.A.B. Levantamento espeleológico do estado de Sergipe: diagnóstico preliminar do município de Laranjeiras. Direto do Centro da Terra, v.1, n.1, p.23-31, 2007.

BARRETO, T.G. et al. Dinâmica da biomassa e do carbono em fragmento urbano de Floresta Ombrófila Mista. Enciclopédia Biosfera, v.10, n.18, p.1300, 2014.

BORGES, R.A. et al. Estoque de carbono em área de pastagem em restauração com espécies do bioma Mata Atlântica no Litoral do Paraná. Floresta, v.48, n.2, p.183-194, 2017.

BRITEZ, R.M. et al. Estoque e incremento de carbono em florestas e povoamentos de espécies arbóreas com ênfase na floresta atlântica dosul do Brasil. Colombo: Embrapa Florestas, 2006.

CHANG, M. Sequestro de Carbono Florestal: oportunidades e riscos para o Brasil. Revista Paranaense de Desenvolvimento, n.102, p.85-101, 2002.

CHAZDON, R. Regeneração de florestas tropicais. Boletim do Museu Paraense Emílio Goeldi Ciências Naturais, v.7, n.3, p.195218, 2012.

CORTE, A.P.D. et al. Os projetos de redução de emissões do desmatamento e da degradação florestal (REDD). Revista Floresta, v.42, n.1, p.177-188, 2012.

MIRANDA, D.L.C. Modelos matemáticos de estoque de biomassa e carbono em áreas de restauração florestal no sudoeste paulista. 2008. 130p. (Dissertação de mestrado).

MOGNON, F. Dinâmica de estoque de carbono como serviço ambiental prestado por um fragmento de Floresta Ombrófila Mista Montana, localizada no Sul do Estado do Paraná. 2011. 125p. (Dissertação de mestrado).

NOSSACK, F.A. et al. Definição de áreas prioritárias para a recuperação florestal visando 92 conectividade entre fragmentos: Análise Multicriterial. 15o Simpósio Brasileiro de Sensoriamento Remoto - SBSR, p.4062-4069, 2011.

PEREIRA, I.C.N. Estoque da biomassa e carbono florestal em unidade de paisagem na Amazônia: uma análise a partir da abordagem metodológica, ecologia da paisagem. 2013. 179p. (Tese de doutorado).

RIBEIRO, S.C. et al. Quantificação de biomassa e estimativa de estoque de carbono em uma capoeira da zona da mata mineira. Revista Árvore, v.34, n.3, p.495-504, 2010.

SANQUETTA, C.R. et al. Relações individuais de biomassa e conteúdo de carbono em plantações de Araucaria angustifolia e Pinus taeda no sul do estado do Paraná, Brasil. Revista Acadêmica: ciências agrárias e ambientais, v.1, n.3, p.33-40, 2003.
SANQUETTA, C.R. et al. The role of forests in climate change. Revista de Ciencias Forestales, v.19, n.1-2, p.84-96, 2011.

SANQUETTA, C.R. et al. Estimativa de carbono individual para Araucaria angustifolia. Pesquisa Agropecuária Tropical, v.44, n.1, p.1-8, 2014.

SANQUETTA, C.R. et al. Estoque de carbono e remoção de em povoamentos jovens de restauração florestal em Rondônia. Nativa, 2018. (no prelo)

SERGIPE. Ministério do Interior: Conselho de Desenvolvimento de Sergipe. Zoneamento ecológico - florestal do estado de Sergipe. Aracaju, 1976.

SFB - SERVIÇO FLORESTAL BRASILEIRO. Florestas do Brasil em resumo. 2010: dados de 2005-2010. Brasília: SFB, 2010.

SFB - SERVIÇO FLORESTAL BRASILEIRO. Inventário florestal nacional: Sergipe. Brasília: MMA, 2017.

SILVA NETO, A. J. Estratificação para estudo de dinâmica, estrutura e volumetria em Cerrado Senso Stricto. 2011. 153p. (Dissertação de mestrado).

SILVA, H. F. Biomassa e carbono no estrato arbóreo em área de restauração e em floresta Semidecidual. 2014. 64p. (Dissertação de mestrado).

SOUZA, A. L. et al. Estrutura fitossociológica, estoques de volume, biomassa e dióxido de carbono em floresta estacional semidecidual. Revista Árvore, v.36, n.1, p.169-179, 2012.

VIEIRA, G. et al. Teores de carbono em espécies vegetais da Caatinga e do Cerrado. Revista Acadêmica Ciências Agrárias e Ambiental, v.7, n.2, p.145-155. 2009.

ZIEMMER, J.K. et al. Quantificação da biomassa e dos teores de carbono de pteridófitas arborescente em floresta Ombrófila Mista. BIOFIX Scientific Journal, v.1, n.1, p.60-73, 2016.

WATZLAWICK, L.F. Estimativa de biomassa e carbono em Floresta Ombrófila Mista e plantações florestais a partir de dados de imagens do satélite Ikonos II. 2003. 120p. (Tese de doutorado).

WATZLAWICK, L. F. et al. Variação nos teores de carbono orgânico em espécies arbóreas da Floresta Ombrófila Mista. Floresta e Ambiente, v.18, n.3, p.248-258, 2011.

Recebido em 16-09-2019 Aceito em 15-11-2019 